Word count (excluding table and references): 6747 


\title{
Exploring relational engagement practices in stroke rehabilitation using the Voice Centred Relational Approach
}

\begin{abstract}
While discussions on patient engagement commonly focus on patient behaviors, a small body of research highlights the patient-practitioner relationship as critical in engagement. Understanding this relationship might be facilitated through a relationally-oriented methodology. The Voice Centred Relational Approach is one such qualitative methodology. Within this paper, we present one turn in a long conversation about this methodology. Drawing on our longitudinal observational study of engagement practices in stroke rehabilitation in New Zealand, we explicate how a theoretical framework can inform how the Voice Centred Relational Approach is enacted in the research process, from entering the field to dissemination. We detail how we adapted the associated analytic techniques (the Listening Guide and i-poems) for use with multiple forms and sources of data. We propose that the underlying relational ontology and relational orientation of this methodology makes it a useful approach in researching relational practice in healthcare.
\end{abstract}

\section{Introduction}

'Engagement' is a term increasingly used in healthcare. It has commonly been conceptualised as a patient behaviour and responsibility (e.g. Author, 2015). Over the last four years, the authors have been researching how engagement is conceptualised and enacted with people experiencing communication disability in stroke rehabilitation services. Our work commenced with a conceptual review which indicated engagement was a co-constructed process and state (Author, 2015). Practitioners were identified as playing a pivotal role in engagement. The relationship between the patient and practitioner, and the interpersonal communication between them, appeared particularly important. An interview-based study we completed with people experiencing communication disability and rehabilitation practitioners in Auckland, New Zealand suggested the process of engagement functioned as a way of working on the part of the practitioner (Author, 2016). Practitioners appeared to intentionally work in particular ways to facilitate engagement. Their actions, and the patient's interpretations and responses to these appeared crucial in the engagement process. The practitioner's actions, however, were informed by their own values, skills and attitudes, and by the systems in which they worked. The process of engagement was a multilayered and often hidden process which people struggled to describe in detail. This led us to explore the process of engagement, and in particular, how practitioners within publically funded rehabilitation services worked to engage people after stroke, and the role of the relationship in the engagement process. We wished to develop rich detailed descriptions of engagement practices, the ways of working undertaken to support engagement. We sought a methodology congruent with this relational focus which would allow detailed description of relationships and clinical practice that would support practitioners to reflect on their own practice and make changes where appropriate. The Voice Centred Relational Approach fulfilled these criteria.

The Voice Centred Relational Approach is a qualitative methodology which emphasises the voices ${ }^{1}$ of research participants. It is based on the premise that a person's 'voice' is "polyphonic and complex"

\footnotetext{
' Voice refers to perspectives (Brown, Debold, Tappen, \& Gilligan, 1991; Sorsoli \& Tolman, 2008) or stories (Mauthner \& Doucet, 1998) embedded within a person's communication.
} 
(Brown \& Gilligan, 1993, p. 15), that an individual might experience multiple, sometimes contradictory ways of thinking about and understanding situations (Brown \& Gilligan, 1993). In this approach, how a person speaks (and indeed, does not speak) of their experiences, themselves, others and relationships provides insight into their perceptions and experiences. A person's voice is influenced, and potentially silenced by the contexts surrounding them, such as societal and cultural frameworks (Brown et al., 1991; Brown \& Gilligan, 1991; Mauthner \& Doucet, 1998).

To attune to the multiplicity of voices within a person's narrative, Brown and Gilligan developed a Listening Guide which involves four sequential readings (or 'Listenings' ${ }^{2}$ ) to attend to the different voices and how they developed (Brown et al., 1991; Brown \& Gilligan, 1992; Gilligan, Spencer, Weinberg, \& Bertsch, 2005). This is a flexible tool customised to the researcher's theoretical perspective and research question (Gilligan et al., 2005; Mauthner \& Doucet, 1998). The first reading of data focuses on the broad story and context evident within the narrative while simultaneously considering the researcher's own response to this story. The second reading focuses on how the person speaks of themselves, exploring the voices within the narrative. Within this reading, i-poems can be created. These are poetic forms constructed using direct quotes which contain personal pronouns such as ' $\mathrm{l}$ ' or ' $\mathrm{me}$ ' and are said to help the researcher tune into how the person speaks of themselves and the voices within their speech (Gilligan et al., 2005). The third and fourth readings are where methodological diversity and analytic flexibility become apparent. For example, Mauthner and Doucet consistently read for relationships (third reading) and social contexts (reading four) (Doucet \& Mauthner, 2002, 2008; Mauthner \& Doucet, 1998, 2003). In contrast, Brown and Gilligan focused on voices of care (reading three) and justice (reading four) informed by earlier research which indicated these voices were consistently present in stories of moral development, and in particular moral theories of care and justice (Brown et al., 1991; Brown \& Gilligan, 1992; Gilligan et al., 2005). These examples demonstrate how the Voice Centred Relational Approach, through the use of the Listening Guide as the primary analytic tool, functions as a research framework informed by the epistemological and ontological assumptions of the researcher rather than being a fixed prescription for how research must occur.

The analytic techniques associated with the Voice Centred Relational Approach, in particular, the Listening Guide and i-poems, have been discussed in a range of qualitative studies. They have been used in longitudinal research (Edwards \& Weller, 2012), as an analytic tool with written reflections (Petrovic, Lordly, Brigham, \& Delaney, 2015) and interview data (Mauthner \& Doucet, 1998), and as a prompt for discussion within focus groups (Nind \& Vinha, 2016). These techniques have often been discussed with little or no reference to the broader, theoretically informed methodology, which we refer to as the Voice Centred Relational Approach (e.g. Koelsch, 2012; Petrovic et al., 2015; Woodcock, 2010). Indeed, some studies describe the Listening Guide as a methodology in its own right (e.g. Woodcock, 2010). While the close attention to analytic techniques has made a valuable contribution to developing these methods, it has also resulted in blurring between methodology and methods. There has been less attention to the theoretical framework underpinning the study, or to the methodology, which Crotty (1998) described as the plan of action for how the research proceeds, and includes the whole research process: such as entering the field, data generation, data analysis and dissemination.

Within our study, we sought to implement the Voice Centred Relational Approach in a theoretically informed way, applying it with a large data set with multiple data sources. While the literature

\footnotetext{
${ }^{2}$ The terms 'readings' or 'listenings' are used interchangeably in the literature. Throughout this paper, We use the term 'readings', consistent with Mauthner and Doucet's (1998) approach.
} 
explores how the Voice Centred Relational Approach can be applied in different settings (e.g. Byrne, Canavan, \& Miller, 2009; Mauthner \& Doucet, 1998), there is a need to better articulate how this approach can function as a methodology, making the theoretical framework explicit and demonstrating how this influences the research process (Mauthner \& Doucet, 1998). Within this paper, we detail our understandings of how the Voice Centred Relational Approach can function as a methodology, situated within a coherent, robust theoretical framework. What we propose is only one way of using this approach. We wish to add clarity to the methodology-method blurring, adding one turn in what is a long and robust scholarly conversation about the Voice Centred Relational Approach, and its associated analytic techniques, the Listening Guide and i-poems. We will demonstrate how these can be used in a multi-faceted, longitudinal study of practice, demonstrating new ways in which these techniques can facilitate understandings.

\section{Explicating and applying the theoretical framework in observational research}

The Voice Centred Relational Approach has been positioned within a number of theoretical perspectives - feminist standpoint theory, literary, narrative and relational theories to name a few (Brown et al., 1991; Brown \& Gilligan, 1993; Gilligan et al., 2005; Mauthner \& Doucet, 1998; Sorsoli \& Tolman, 2008). However, the ontological and epistemological underpinnings of the approach have predominantly been implicit (Mauthner \& Doucet, 2003). It has been argued that ontology, epistemology and theoretical perspectives are so closely entwined that each component is rarely discussed separately(Doucet \& Mauthner, 2002; Mauthner \& Doucet, 2003). As a result, there has been limited attention to how these are enacted within, or influence, the research process (Doucet, 1998; Doucet \& Mauthner, 2002). While this entanglement is not unusual, it can make it challenging for researchers who are new to the methodology to grapple with the theoretical framework which underpins it, or who wish to tailor the Voice Centred Relational Approach to their own theoretical framework (Gilligan et al., 2005). Drawing on Mauthner and Doucet's work (e.g. Doucet, 1998; Doucet \& Mauthner, 2002; Mauthner \& Doucet, 1998), we situated our study within a theoretical framework comprising a relational ontology, social constructionism and symbolic interaction. Within this section, we detail the key components of the theoretical framework and demonstrate how they were applied in this study of engagement practices.

The Voice Centred Relational Approach is based on a relational ontology (theory of being) (Doucet, 1998; Doucet \& Mauthner, 2002; Mauthner \& Doucet, 1998). Relational ontology holds that humans exist within relationship, embedded in interdependent intimate and large social relations (Gilligan et al., 2005; Mauthner \& Doucet, 1998; Tronto, 1995). Relationships form the basis of humanity, as well as our understandings of ourselves (Nortvedt, Hem, \& Skirbekk, 2011). Within a Voice Centred Relational Approach, the researcher has a relationship with the participants throughout the research process. For instance, Brown and colleagues (1991) argued analysis is a relational act. Within analysis, the Voice Centred Relational Approach focuses on relational aspects of the phenomenon under consideration, closely attending to relationship: those between the voices in each participant's data, between the participant and those around them, and with the contexts surrounding them (Doucet, 1998; Doucet \& Mauthner, 2002; Mauthner \& Doucet, 1998, 2003). As a result, Voice Centred Relational research has been described as having a "relational filter" (Doucet \& Mauthner, 2002, p. 12), reading for relationship in the data, prioritising relational issues within analysis, and producing a relational interpretation. The relational ontology appeared consistent with our early work on engagement (Author, 2015), which highlighted relationship appeared crucial in engagement but there had been limited research exploring these relational processes. 
Within the Voice Centred Relational Approach, knowledge is viewed as socially constructed. People are embedded within larger social relations; the knowledges participants hold are situated and constructed in interaction with social and cultural frameworks that surround them (Gilligan et al., 2005; Mauthner \& Doucet, 1998). Knowledges are contextual and multi-layered, reflecting multiple constructed realities (Berger \& Luckmann, 1967; Mauthner \& Doucet, 1998). Research knowledge is considered developmental, partial and situated in the context in which it was constructed between the researcher and participant/s (Berger \& Luckmann, 1967; Mauthner \& Doucet, 2003). Participants are only ever partially known; arguably it is not possible to claim to know the participant and their lived experience, instead only being able to "grasp something of their articulated experience and subjectivity" (Mauthner \& Doucet, 2003, p. 423). Researchers themselves are socially located. Doucet (1998) stated this influences how researchers "'see' and 'hear' the individuals [and] how we construct theory from their words, experiences and lives" (p. 54). They actively construct knowledge by attending to particular voices in the data (Doucet \& Mauthner, 2002) a responsive and relational act, which reflects the relational ontology of the research and demonstrating how ontology and epistemology are closely entwined.

While the Voice Centred Relational Approach may draw on a range of different theoretical perspectives as detailed above, Mauthner and Doucet (1998) suggested it is "firmly rooted ... in a symbolic interactionist tradition" (p. 27), as evident in the focus on the self, exploring meaning, actions, and social interaction. The Listening Guide can support researchers to closely attend to the self by focusing on voices within the participant's narratives, considering how a person sees and presents themselves, the meanings they hold and how these developed (Brown et al., 1991; Mauthner \& Doucet, 1998). People's meaning-making becomes evident in how they speak of themselves and their actions (Gilligan et al., 2005; Mauthner \& Doucet, 1998). Relationships are considered a key context in which people construct meaning (Gilligan et al., 2005; Sorsoli \& Tolman, 2008), reflecting a process of social interaction where actors (which includes people and institutions or services) are seen to "take one another into account, symbolically communicate to one another and interpret each other's actions" (Charon, 2010, p. 138). Within this research, we considered that attending to social interaction and joint action, how patients and practitioners spoke of the self and the objects in their environments, understanding the processes of meaning-making and on-going action may help "bring to life the essence and character of a [person's] experience and behavior" (Halligan \& Marshall, 1996, p. vii). Symbolic interactionist principles of exploration (developing an understanding of what is happening) and inspection (detailed descriptions of what happens, how these actions relate to what people are thinking and considering the consequences of actions) (Blumer, 1969) could facilitate deep understandings of engagement practices which would further knowledge in this area.

This theoretical framework provided the scaffold for our research design and conduct. As the Voice Centred Relational Approach is a framework rather than a prescription for how research should be conducted, we then needed to apply this theoretical framework to construct a methodology, the "map of action" (Crotty, 1998, p. 7) for how this longitudinal, observational study of engagement would proceed. To do this, we utilised the core principles from the theoretical framework. These included:

- Researchers and participants are in on-going relationships throughout the research process.

- People exist in inter-dependent relationships with themselves, with others and with their context.

- Knowledge is constructed through interaction with the self, with others and with the broader context that the researchers and participant/s are located in. 
- People act in response to the meanings objects hold; these meanings are constructed through social interaction and can be ever-changing.

- Multiple constructed realities exist. Accordingly, knowledge is multi-layered and never complete. It is always partial and situated within the context it is constructed in.

These principles, together with the more nuanced readings of the theoretical framework were then applied at different "decision junctures" (Koro-Ljundberg, Yendol-Hoppey, Smith, \& Hayes, 2009, p. 688 ) in the research process, thus forming the methodology for this research.

\section{Entering and being in the research: Researchers in relationship with the participants} The research process is a "relational encounter" (Kiegelmann, 2009, p. 6) with the researcher an active participant in the process (Gilligan et al., 2005). The theoretical framework prompted us to attend to the relationship between the participants and researcher. Gilligan suggested the individual's voices are very responsive to the outside world, that a tense research situation or relationship could constrain or flatten participant voices (Hamer, 1999). Our relationships with participants were integral throughout this research and influenced how we entered the field, developing relationships through whakawhanaungatanga " "allowing time and space to establish relationships" (Jones, Crengle, \& McCreanor, 2006, p. 70). We spent time with participants, meeting multiple times before completing consent, attending to our relationship during data collection by spending time talking with them and their families, and sharing some information about ourselves. In a sense, this reflected a process of engaging research participants in the research process before then studying how they engaged in their rehabilitation, reflecting a view that developing relationships helped create a relational research environment which might facilitate communication and understanding of people's experiences (Jankowski, Clark, \& Ivey, 2000; Latimer, 2000; Morrow, 2005). We also considered ourselves in on-going relationships throughout analysis and dissemination, recognising that we actively constructed knowledge by attending to particular voices in the data (Doucet \& Mauthner, 2002).

\section{Recruitment and sampling: Determining who are participants}

Viewing people as being entwined in inter-dependent relationships (Mauthner \& Doucet, 1998; Tronto, 1995) prompted us to recruit people experiencing communication disability and their rehabilitation practitioners. The vast majority of engagement research has focused on perspectives of practitioners or patients (Author, 2015) rather than incorporating the perspectives of patients and practitioners. Accordingly, patients, their families and rehabilitation practitioners were recruited as participants with data gathered from patient-practitioner dyads (i.e. pairings of consenting patients and consenting practitioners). We recruited 28 rehabilitation practitioners and three people experiencing communication disability throughout four separate episodes of rehabilitation, each lasting between two and 14 weeks. This resulted in 28 patient-practitioner dyads. The study was based in inpatient and community stroke rehabilitation services.

\section{Data generation: Co-constructing knowledge with participants}

Blumer (1969) stated direct examination of the participant's world is essential to understand how they make meaning and act. Accordingly, this study combined multiple data collection methods:

\footnotetext{
${ }^{3}$ Whakawhanaungatanga is a Māori term, Māori being both the indigenous population and official language of New Zealand. The term reflects a depth and commitment to the process of relationship-building beyond the term 'building relationship', and is used in response to where the research was culturally located.
} 
participant observation, stimulated recall, and informal and formal interviews with both parties. Data generation was led by the first author (FB). Each method of data generation elicited subtly different understandings of how people acted together and separately, how they constructed meaning, how they acted in relationship with others and how they made decisions about engagement based on their interactions within each individual, and between members of each dyad (Berger \& Luckmann, 1967; Blumer, 1969; Mauthner \& Doucet, 1998). Collecting different forms of data allowed consideration of both talk-about-action ${ }^{4}$ (in interviews and stimulated recall sessions) and talk-in-action ${ }^{5}$ (in observations of interactions) and helped highlight the tensions and complexities inherent in engagement. It also highlighted poly-vocality, the different voices and perspectives within a person's way of working and talking about working (Gilligan et al., 2005; Mauthner \& Doucet, 1998).

Observing interactions enabled detailed description and exploration of actions as well as how participants constructed meaning within interactions, what behaviors they attended to and acted on, what roles they took and what their actions accomplished (Blumer, 1969; Charon, 2010). The observations focused on the interactions and relationships between participants within each dyad, and between participants and their context (Doucet, 1998; Doucet \& Mauthner, 2002; Mauthner \& Doucet, 1998, 2003). Observing people within their everyday contexts gave insight into the social and cultural frameworks surrounding them (Gilligan et al., 2005; Mauthner \& Doucet, 1998). In total, 147 hours of observation occurred. Stimulated recall interviews elicited the reasoning that underpinned action (Gass \& Mackey, 2000). Videos of patient-practitioner interactions were the stimulus for the interview. These explored why people did what they did and how they perceived and reacted to the actions of others. Eliciting participants' thought processes and feelings provided insight into the objects people attended to, how they interpreted them and how they responded (Blumer, 1969; Gass \& Mackey, 2000; Gilligan et al., 2005; Mauthner \& Doucet, 1998). Informal and formal interviews explored each participant's experiences and perceptions of engagement, exploring how participants developed knowledge, their meaning-making and action(Charon, 2010), and the structures influencing rehabilitation (Berger \& Luckmann, 1967; Blumer, 1969; Gergen \& Gergen, 2007).

\section{Analysing data: Constructing knowledge(s) and understanding(s)}

Data analysis was iterative, occurring firstly within each patient-practitioner dyad and then across all participants. The Voice Centred Relational Approach offers a flexible, principle-based approach to analysis (Gilligan et al., 2005; Kiegelmann, 2009; Mauthner \& Doucet, 1998) with the theoretical principles of the research underpinning the way in which analysis occurred. The Listening Guide is a useful tool for supporting the analysis process and was the primary method of analysis used throughout this research. Previously both the Voice Centred Relational Approach and the Listening Guide have been used with relatively small sets of interview-based data. The specific questions within each reading were informed by the theoretical framework which underpinned the study (see Table One).

--- Insert Table One here ---

\footnotetext{
${ }^{4}$ Talk-in-action refers to how the practitioner communicated (verbally or non-verbally) when interacting with the person experiencing communication disability.

${ }^{5}$ Talk-about-action refers to how the practitioner spoke about their practice within interviews outside the I:I interaction with the patient. Talk-about-action represented the practitioner's reported perceptions of, and reasoning about their practice.
} 
The first twelve dyads were selected as they were representative of all dyads by profession and clinical experience, and there were multiple patient-practitioner interactions and multiple forms of data gathered throughout the patient's episode of care. The first reading of each dataset involved attending closely to the stories in the data and our own response to these, asking 'what is going on here?'(Mauthner \& Doucet, 1998). Attending to our responses made our role in constructing knowledge explicit and reflects our relationship with the participant and the data, and that our own social location influences how we construct the data (Mauthner \& Doucet, 1998). The reading was then summarised into a memo, as demonstrated in this analysis of an interaction between a patient and doctor:

When Betty continues to ask "maybe I can go home", the content of Mike's talk focuses on the rehabilitation process with comments such as "it's part of the deal here I'm afraid", "But we'd like all of the [multidisciplinary team] to have a chance to assess you over a period of days and then we'll all meet with the family and the medical team and the disciplines and then we'll try and make a plan" and "we usually like to have a bit more time to assess you before we make definitive decisions". The rehabilitation process dominates, with talk of assessments, meetings and plans. $1^{6}$ can't help but attend to how the practitioners seem to have power and expert knowledge. I wonder where Betty's voice is in this process. This contrasts with what Mike tells me in an interview: "all you can do is give her the options and the information. You have to respect her wishes. It's important to go with what she thinks is right, we need to let her try and make a decision"7.

These memos documented as similarities and differences across the dataset. They recorded what practitioners did with patients (talk-in-action) and how they talked about what they did (talk-aboutaction), and captured the practitioner's talk and action in different contexts, such as with the patient, in team meetings or in family meetings.

291 The remaining readings of the Listening Guide focused on exploring selected data (Mauthner \&

292 Doucet, 1998), selected for reasons such as: the data appeared to offer particular insight into engagement; there was a range of data sources for an interaction; or because there were marked contradictions between talk-in-action and talk-about-action. The second reading focused on the voices of the participant, how they spoke of themselves, the different ways they acted and the roles they played (Berger \& Luckmann, 1967; Gergen \& Gergen, 2007). Analysis attended to how people created meaning and how these meanings influenced action (Blumer, 1969). Attending to body language and tone of voice prompted consideration of how people spoke of themselves in talk and in action.

As part of the process of completing the first reading and becoming attuned to the voices in the text, i-poems were constructed from the data. Using i-poems and presenting contrasting voices highlights the different voices (Edwards \& Weller, 2012; Gergen \& Gergen, 2007; Gilligan et al., 2005; Mauthner \& Doucet, 1998), helping people "hear more of [the participants'] voices and understand more of their perspective" (Mauthner \& Doucet, 1998, p. 26). Attending to poly-vocality within the data in this study prompted consideration of multiple realities and perspectives (Gergen \& Gergen,

\footnotetext{
${ }^{6}$ The pronoun 'I' reflects the memo was written by one member of the research team (FB)

${ }^{7}$ This memo incorporates a description of an interaction incorporating direct quotations from participants (indicated in quote marks) as well as the researcher's perceptions and very early analysis of the interaction.
} 
2007; Gilligan et al., 2005; Mauthner \& Doucet, 1998) as evident in these two i-poems, one taken from an interaction between Betty (patient) and Mike (doctor), and one taken from an interview with Mike:

If you keep making progress, it won't be long

We'd like all of the team to assess you

Then we'll meet with the family and the medical team and the disciplines

Then we'll make a plan

(i-poem, Mike, ward round)

All you can do is give her the options and the information

You have to respect her wishes

All we can do is give her the information

It's important to go with what she thinks is right

Ultimately it's her decision

Let her try and make a decision

(i-poem, Mike, interview)

These two contrasting i-poems depict voices of power and control in Mike's talk with Betty, and responsive, patient-centred voices in his interview. The i-poems helped highlight the voices of participants, capturing how they positioned themselves in relation to others.

The third and fourth readings were informed by the theoretical framework and Mauthner and Doucet's research (Doucet, 1998; Doucet \& Mauthner, 2002, 2008; Mauthner \& Doucet, 1998). The third reading focused on how each person spoke of the 'other' (people in their environment), relationships, and in particular, relationships between themselves and others in their environment. This reflected the relational ontology underpinning the study as well as the position that knowledges are socially constructed through interaction. 'Other-poems' (poems centred on the personal pronouns used to refer to others and the relationships between them) explored how people spoke of the other, as evident in one poem constructed from a patient's description of staff who he struggled to engage with:

They scurry over and turn me

They walk away not even putting the bed rails up

I have to ask them to do it

They don't want to talk

I think they feel awkward because I can't talk back

They've not even tried

(i-poem, Peter, interview)

While these 'other-poems' are not an established component of the Voice Centred Relational Approach, they facilitated close attention to the relational aspects of practice. Analysis considered how participants spoke (and didn't speak) of the 'other' and of relationships in both their verbal and non-verbal action. This reading considered who was present and included in interactions, whose opinions appeared to hold weight or who was silenced.

The fourth and final reading focused on the socio-cultural context, considering interactions between individuals and their context, asking what appeared to be taken-for-granted and how this came to be, what were dominant ways of working, and what was privileged and why this was, informed by Latimer's $(2000,2008)$ critical constructionism. Analysis considered how contextual factors were evident in, and appeared to influence practitioners' ways of working. It considered how profession- 
based and organisational structures and the physical environment were evident in practitioner and patient talk, action and meaning-making.

The analysis from these readings were then incorporated into the memo created after the first reading of the data, a record of the developing analysis ${ }^{8}$ :

\begin{abstract}
When Betty continues to ask "maybe I can go home", the content of Mike's talk focuses on the rehabilitation process with comments such as "it's part of the deal here I'm afraid", "But we'd like all of the [multidisciplinary team] to have a chance to assess you over a period of days and then we'll all meet with the family and the medical team and the disciplines and then we'll try and make a plan" and "we usually like to have a bit more time to assess you before we make definitive decisions". In this, Mike positions himself as an empathiser, but not a negotiator (e.g. 'it's part of the deal I'm afraid), and Betty as someone who is expected to go with the flow. The rehabilitation process dominates, with talk of assessments, meetings and plans. THE REHAB PROCESS IS ALMOST AN ENTITY OF ITS OWN. REHABILITATION IS ABOUT ASSESSMENT; WHAT IS NOT CLEAR IS WHAT IS BEING ASSESSED AND WHAT THE BENCHMARK OR TARGET IS - IT ALL FEELS VERY NEBULOUS AND NON-NEGOTIABLE. THE LANGUAGE USED IS THE SYSTEM'S LANGUAGE - THE "MDT"; the patient is relatively silent, especially when Mike talks of the meeting: "we'll all meet with the family and the medical team and the disciplines and then we'll try and make a plan". Is she included in the "we"? It is all about her after all - Betty is positioned as having responsibility for the decision about going home - responsibility in the terms of 'If you keep making progress, it won't be long'. If she wants to go home, she needs to progress. It is interesting to see who is not spoken of - Betty. There is no mention of her as a player other than as a subject of assessment.
\end{abstract}

Each memo contained reflections on the research question, asking 'how do rehabilitation practitioners engage people experiencing communication disability in stroke rehabilitation?', while also summarising how practitioners worked, why they worked as they did and what this accomplished. This helped us start to explore the engagement practices evident within the data. This analytic memo then formed the basis for analysis across participants. Comparing and contrasting voices of individual participants and patient-practitioner dyads over the course of rehabilitation, often using i-poems, highlighted the relational and co-constructed nature of engagement and disengagement in rehabilitation, as illustrated in i-poems from Peter (patient participant) and Cathleen (rehabilitation practitioner):

I hate [therapy] (i-poem, Peter, informal interview, week one)

$$
\begin{array}{r}
\text { A mediocre session } \\
\text { There's a bit of engagement but not a lot } \\
\text { He sort of shut off } \\
\text { I hit a brick wall } \\
\text { It's almost like 'why try?' } \\
\text { When he's not engaging I think 'what am I doing wrong' } \\
\text { I think more about myself than him } \\
\text { (i-poem, Cathleen, informal interview, week one) }
\end{array}
$$

\footnotetext{
${ }^{8}$ Reading one (reading for the story) is in bold. Reading two (reading for the self) is in italics. Reading three (reading for the other) is in grey. Reading four (reading for the context) is in capitals.
} 
Hate it, didn't want to try

If she'd backed off

I'm just tolerating it

Feeling negative

(i-poem, Peter, informal interview, week four)

I didn't want to come back after Easter

It's just been too hard He's not engaged

He's not enjoying it

I'm not sure what to do

(i-poem, Cathleen, informal interview, week four)

\author{
I'm achieving \\ I'm rapt \\ It's magic \\ I'm finally feeling positive \\ Now, now it's good \\ (i-poem, Peter, informal interview, week eight)
}

\author{
It's such a nice feeling \\ He was so interested to talk to me \\ It was so natural, so nice \\ My engagement is a lot easier \\ I can feel the success \\ I can see the change, the progression \\ I feel that what we're doing makes a difference \\ So I feel more engaged \\ (i-poem, Cathleen, informal interview, week eight)
}

Analysis continued in an iterative process of constant comparison (Charmaz, 2014), moving between analysing individual participant datasets and comparative analysis between datasets until the first 12 datasets were analysed. While constant comparison has not been described as a core component of the Voice Centred Relational Approach, it helped identify similarities and differences in practice within and across participants and leading to more comprehensive and nuanced understandings of the components of these practices. Throughout the course of analysis, understandings of how practitioners worked were challenged, developed and modified. Memos and mindmaps captured the emerging analysis.

\title{
Analysis of the remaining dyads
}

The subsequent sixteen dyads were analysed in two groups. The first group of eight dyads were chosen based on our detailed case knowledge and emergent informal analysis that occurred during data collection (Mauthner \& Doucet, 1998); the final analysis focused on eight dyads from whom there was limited data. For the first eight dyads, the analysis process occurred as detailed for Stage One above, except that the four readings of the Listening Guide were completed concurrently and then integrated into a memo. Comparative analysis continued as detailed in Stage One of data analysis. The twin tools of memoing and constant comparison resulted in increasingly complex, 
nuanced understandings of how practitioners worked to engage the patient in stroke rehabilitation. Mindmaps were used to visually represent relationships between actions, and between ways of thinking and acting. Data from the final eight dyads were primarily used for constant comparison. Datasets were reviewed and brief notes were taken. These focused on the Listening Guide questions of 'what is happening here?', 'how do they speak of themselves?', 'how do they speak of others and of relationships?' and 'how do they speak of the context?'. These summaries were then compared with the analysis completed to that point. While the new data did not identify any new ways of working, they did result in deeper understandings of engagement practices.

\section{Presenting findings}

Participant perspectives are embedded throughout the research findings (Author 2016, 2017). This was done in part to ensure their voices were not dominated by our voices as researchers, a key principle in presenting research in a Voice Centred Relational Approach (Mauthner \& Doucet, 1998). It can be difficult for people experiencing communication disability to be heard in research and practice (e.g. Parr, Byng, Gilpin, \& Ireland, 1997); foregrounding their perspectives was an ethical concern. The findings detail similarities and differences within and across participants, demonstrating poly-vocality (Brown et al., 1991; Brown \& Gilligan, 1992; Gergen \& Gergen, 2007; Gilligan et al., 2005; Mauthner \& Doucet, 1998). When we present findings, informal feedback suggests i-poems are a powerful tool in helping people attend to the voices and the experiences of people, reflecting Nind \& Vinha's (2016) experience that i-poems helped provoke transformative dialogue. This demonstrates how analysis can facilitate, and indeed be a form of dissemination, and can help draw listeners into relationship with the participants and their experiences.

\section{Discussion}

This paper details how the Voice Centred Relational Approach was used in a study of engagement practices in stroke rehabilitation. Our purpose was to make the theoretical framework explicit by demonstrating how it informed the research process, and by detailing how this approach was used with large datasets with multiple forms and sources of data. While the Voice Centred Relational Approach is an established research approach, the methodology and theoretical framework that underpins the research have commonly been implicit and taken for granted (Mauthner \& Doucet, 2003) despite these being essential in developing and implementing research methodology (Crotty, 1998). We contribute to the scholarly conversation on this research approach by demonstrating how we applied a theoretical framework to this research, in the tradition of Mauthner and Doucet (1998). This is likely to be of use to those considering this approach in the future. This is not to say that the theoretical framework we drew on is the only one that can be used. The inherent flexibility of the Voice Centred Relational Approach makes it a useful research approach. Indeed, many authors have drawn on different theoretical perspectives and integrated different theories in developing the Listening Guide, depending on their specific focus (e.g. Brown \& Gilligan, 1992; Mauthner \& Doucet, 1998; Sorsoli \& Tolman, 2008). However, we argue there is a need to make the methodology and theoretical perspectives transparent and ensure there is coherence and consistency across the research process (Crotty, 1998; Tracy, 2010). We hope that explicating our use of a theoretical framework will support others seeking to use this approach in the future.

The Voice Centred Relational Approach has primarily, but not exclusively been utilised with relatively small sets of interview-derived data. The large dataset and multiple forms of data in this study posed some challenges as there was a lack of specific guidance on how to enact this approach in a robust, 
methodical manner. Modifying the process to intentionally capture and compare verbal and nonverbal communication, and to compare action, talk-in-action and talk-about-action enabled close examination of practice and facilitated crystallisation (Ellingson, 2009). However, we suggest there is potential to further develop this approach, drawing on other theoretical perspectives such as Goffman's face-work (Goffman, 1955) or different research traditions such as Conversation Analysis with its focus on talk-in-interaction. For instance, considering how people are arguing for the positions they hold within interactions might elicit more nuanced understandings of participant's voices. Applying the Voice Centred Relational Approach to observational research has helped develop rich, nuanced understandings of practice, enhancing and extending findings from interviewbased research, but we would argue there is clearly scope for more methodological development in the future.

It should be noted that some of the analysis approaches are not without controversy. The use of poems in analysis and dissemination is not universally supported in qualitative research (Breckenbridge, 2016; Morse et al., 2009). One argument against poetic form seems to focus on its use in dissemination and data representation, without consideration of its role as an analytic technique (Morse et al., 2009). However, the Voice Centred Relational Approach uses poetic form as an analysis approach to provide understandings of how people speak of themselves (Gilligan et al., 2005). Morse and colleagues argue transforming data into poetry changes the form of data. We echo Denzin's (2013) comment that "there can never be a final, accurate, complete representation of a thing, an utterance or an action" (p. 2), that utterances are continually constructed and reconstructed throughout the research process, from interview, within transcription, in analysis and when selecting and presenting selections within publications. In this sense, every time we extract data to support a point, we are inherently changing the form of the data, whether or not we use an i-poem to do so. We suggest i-poems, and other-poems as we used in our research, could be useful in both research and knowledge translation. There is a move toward art-based inquiry and dissemination within health research and in knowledge translation (e.g. Fraser \& al Sayah, 2011; Kontos \& Poland, 2009; Rieger \& Schultz, 2014). We suggest i-poems may be considered an artbased form of dissemination. While informal feedback from research audiences has indicated ipoems help practitioners understand different aspects of engagement, we hope to explore the different uses of i-poems in the future, as a tool in dissemination, and as a way to foster practice reflections.

We used the Voice Centred Relational Approach because we wanted to explore how engagement arose within the relationship and interaction between the patient and practitioner. While other methodologies would have allowed us to explore engagement, the Voice Centred Relational Approach prompted an explicit focus on the relationship between the patient and practitioner, and how each person thought, talked and worked within that relationship. Our findings, reported elsewhere (Author, 2016, 2017), found engagement to be inherently a relational practice occurring within and because of the relationship between the patient and practitioner. The analytic techniques in the Voice Centred Relational Approach, particularly the Listening Guide and i-poems, were integral in the process of identifying core components of relational engagement practices. Foregrounding relationships throughout the research process, from design to methods to dissemination, facilitated close examination of relational aspects of practice. Of course, this may be considered a limitation of the methodology. The relational approach to research, and the specific readings for relationships likely contributed to the strong relational findings, but may have also constrained what we saw (or indeed, did not see). This does not mean that the findings are not valid, however, it should prompt a tentativeness about them. The relational nature of engagement is one aspect of engagement and appears important for many, but not all people experiencing 
537 communication disability. A different methodology or theoretical framework would likely facilitate

538 different understandings of engagement. However, the underlying relational ontology and relational

539 orientation of this methodology makes it a useful approach in researching relational practice in

540 healthcare, or in other contexts.

541

542 Conclusion

543 This paper has detailed how the Voice Centred Relational Approach can be used to examine

544 relational aspects of rehabilitation. The relational ontology and orientation of the research, together

545 with analysis techniques helped us become attuned to the relational aspects of practice helping us

546 develop nuanced yet applied understandings of clinical practice. Using the Voice Centred Relational

547 Approach with patient-practitioner dyads allowed for close investigation of how and why practice

548 occurs as it does, while also considering what it brings about for the parties involved. This approach

549 helps illustrate the inherent complexities of being together in relationships and enacting relational

550 practice, in a manner which is beneficial for the researcher and research audiences alike. Using the

551 theoretical underpinnings of the Voice Centred Relational Approach to develop a robust

552 methodology and theoretically-informed analysis approach has strengthened the analysis, provided

553 nuanced insight into engagement practices, and has contributed to methodological development.

554

555 
Table One. Questions guiding the Listening Guide analysis

\begin{tabular}{|c|c|}
\hline Reading & Questions \\
\hline \multirow{3}{*}{$\begin{array}{l}\text { Reading One: } \\
\text { The story and } \\
\text { response }\end{array}$} & What is going on here? \\
\hline & What are the events, sub-plots, characters, metaphors, and recurrent phrases? \\
\hline & What is my emotional \& intellectual response to the participant? \\
\hline \multirow{8}{*}{$\begin{array}{l}\text { Reading Two: } \\
\text { Participant voices }\end{array}$} & Who is speaking and with what voice? \\
\hline & How does the participant experience, feel, present and speak of themselves? \\
\hline & How does the participant believe others see them? \\
\hline & What emotions, reflections, opinions, actions, intentions are evident? \\
\hline & What pronouns does the person use when speaking of themselves? \\
\hline & $\begin{array}{l}\text { What are people saying and doing (acting)? How do they expect to act? How do they } \\
\text { do things and how did they develop that knowledge? }\end{array}$ \\
\hline & What roles are the participant playing? \\
\hline & $\begin{array}{l}\text { How do they perceive situations, words and actions (symbols)? How does this impact } \\
\text { on action? }\end{array}$ \\
\hline \multirow{6}{*}{$\begin{array}{l}\text { Reading Three: } \\
\text { Others and } \\
\text { relationships }\end{array}$} & $\begin{array}{l}\text { Who is spoken about, the relationships, emotions, statements and stories associated } \\
\text { with each? }\end{array}$ \\
\hline & Who is related to who in what way? \\
\hline & How are people positioned within the relationships and interactions? \\
\hline & $\begin{array}{l}\text { What are people saying and doing (acting)? How do they expect to act? How do they } \\
\text { do things and how did they develop that knowledge? }\end{array}$ \\
\hline & What roles are the participant playing? \\
\hline & $\begin{array}{l}\text { How do they perceive situations, words and actions (symbols)? How does this impact } \\
\text { on action? }\end{array}$ \\
\hline \multirow[t]{7}{*}{$\begin{array}{l}\text { Reading Four: } \\
\text { Context }\end{array}$} & $\begin{array}{l}\text { What are the broader social, political, cultural, professional and structural contexts } \\
\text { surrounding the participants' story, experiences, actions and interpretations? }\end{array}$ \\
\hline & What is spoken and unspoken, overt and taken-for-granted? \\
\hline & Whose voices are heard informing the situation? \\
\hline & What social values surround the interaction? \\
\hline & Why do people act in some ways and not others? \\
\hline & $\begin{array}{l}\text { What is institutionalised? What is the 'right' way to do things? Where did this come } \\
\text { from? How have different roles come about? }\end{array}$ \\
\hline & What is privileged in talk and/or action? \\
\hline
\end{tabular}

560 The authors thank Dr Gareth Terry and the two anonymous reviewers for their assistance in

561 critiquing and revising the manuscript. 


\section{References}

Author (2015)

Author (2016)

Berger, P. L., \& Luckmann, T. (1967). The social construction of reality: A treatise in the sociology of knowledge. New York: Anchor Books.

Blumer, H. (1969). Symbolic Interactionism: Perspective and method. Berkeley, CA: University of California Press.

Breckenbridge, J. P. (2016). The reflexive role of tanka poetry in domestic abuse research. Journal of Research in Nursing, 21(5-6), 447-460. doi:10.1177/1744987116649635

Brown, L. M., Debold, E., Tappen, M., \& Gilligan, C. (1991). Reading narratives of conflict and choice for self and moral voice: A relational method. In W. Kurtines \& J. Gewirtz (Eds.), Handbook of moral behavior and development: Theory, research, and application (pp. 25-61). Hillsdale, NJ: Lawrence Erlbaum.

Brown, L. M., \& Gilligan, C. (1991). Listening for voice in narratives of relationship. New Directions for Child Development, 54, 43-62.

Brown, L. M., \& Gilligan, C. (1992). Meeting at the crossroads: Women's psychology and girls' development. Cambridge, MA: Harvard University Press.

Brown, L. M., \& Gilligan, C. (1993). Meeting at the crossroads: Women's psychology and girls' development. Feminism and Psychology, 3(1), 11-35.

Byrne, A., Canavan, J., \& Miller, M. (2009). Participatory research and the voice centred relational method of data analysis: Is it worth it? International Journal of Social Research Methodology, 12(1), 67-77. doi:10.1080/13645570701606044

Charmaz, K. (2014). Constructing grounded theory (2nd ed.). London, United Kingdom: Sage Publications.

Charon, J. M. (2010). Symbolic interactionism: An introduction, an interpretation, an integration (10th ed.). Boston, MA: Prentice Hall.

Crotty, M. (1998). The foundations of social research. Crows Nest: Allen \& Unwin.

Denzin, N. K. (2013). The death of data? Cultural Studies $\leftrightarrow$ Critical Methodologies, 1-4. doi:10.1177/1532708613487882

Doucet, A. (1998). Interpreting mother-work: Linking methodology, ontology, theory and personal biography. Canadian Woman Studies, 18, 52-58.

Doucet, A., \& Mauthner, N. S. (2002). Knowing responsibly: Ethics, feminist epistemologies and methodologies. In M. Birch, T. Miller, M. Mauthner, \& J. Jessop (Eds.), Ethics in Qualitative Research (2nd ed.). London, United Kingdom: Sage.

Doucet, A., \& Mauthner, N. S. (2008). What can be known and how? Narrated subjects and the Listening Guide. Qualitative Research, 8(3), 399-409. doi:10.1177/1468794106093636

Edwards, R., \& Weller, S. (2012). Shifting analytic ontology: Using I-poems in qualitative longitudinal research [Article]. Qualitative Research, 12(2), 202-217. doi:10.1177/1468794111422040

Ellingson, L. L. (2009). Engaging crystallization in qualitative research: An introduction. Thousand Oaks, CA: Sage.

Fraser, K. D., \& al Sayah, F. (2011). Arts-based methods in health research: A systematic review of the literature. Arts \& Health, 3(2), 110-145. doi:10.1080/17533015.2011.561357

Gass, S. M., \& Mackey, A. (2000). Stimulated recall methodology in second language research. Retrieved from www.aut.Iconz.ac.nz

Gergen, K. J., \& Gergen, M. M. (2007). Social construction and research methodology. In W. Outhwaite \& S. Turner (Eds.), The SAGE handbook of social science methodology (pp. 461478). Thousand Oaks, CA: Sage.

Gilligan, C., Spencer, S. R., Weinberg, K. M., \& Bertsch, T. (2005). On the listening guide: A voicecentred relational method. In S. Hesse-Biber \& P. Leavy (Eds.), Emergent methods in social research (pp. 253-271). Thousand Oaks, CA: Sage. 

neuropsychology. Hove, United Kingdom: Psychology Press.

Hamer, M. (1999). Listen to the voice: An interview with Carol Gilligan. Women: A Cultural Review, 10(2), 173-184. doi:10.1080/09574049908578387

Jankowski, P. J., Clark, W. M., \& Ivey, D. C. (2000). Fusing horizons: Exploring qualitative research and psychotherapeutic applications of social constructionism. Contemporary Family Therapy, 22(2), 241-250. doi:10.1023/A:1007738021412

Jones, R., Crengle, S., \& McCreanor, T. (2006). How Tikanga guides and protects the research process: Insights from the Hauora Tane project. Social Policy Journal of New Zealand(29).

Kiegelmann, M. (2009). Making oneself vulnerable to discovery. Carol Gilligan in conversation With Mechthild Kiegelmann. Forum Qualitative Sozialforschung /Forum: Qualitative Social Research, 10(2). Retrieved from http://nbn-resolving.de/urn:nbn:de:0114-fqs090234.

Koelsch, L. E. (2012). The Virtual Patchwork Quilt: A Qualitative Feminist Research Method [Article]. Qualitative Inquiry, 18(10), 823-829. doi:10.1177/1077800412456957

Kontos, P. C., \& Poland, B. D. (2009). Mapping new theoretical and methodological terrain for knowledge translation: Contributions from critical realism and the arts. Implementation Science, 4(1), 1-10. doi:10.1186/1748-5908-4-1

Koro-Ljundberg, M., Yendol-Hoppey, D., Smith, J. J., \& Hayes, S. B. (2009). (E)pistemological awareness, instantiation of methods, and uninformed methodological ambiguity in qualitative research projects. Educational Researcher, 38(9), 687-699. doi:10.3102/0013189X09351980

Latimer, J. (2000). The conduct of care: Understanding nursing practice. Malden, MA: Blackwell Science.

Latimer, J. (2008). Critical constructionism in nursing research. In J. A. Holstein \& J. F. Gubrium (Eds.), Handbook of constructionist research (pp. 153-170). New York, NY: Guildford Press.

Mauthner, N. S., \& Doucet, A. (1998). Reflections on a Voice-Centred Relational Method of data analysis: Analysing maternal and domestic voices. In J. Ribbens \& R. Edwards (Eds.), Feminist dilemmas in qualitative research: Private lies and public texts (pp. 119-144). London: Sage.

Mauthner, N. S., \& Doucet, A. (2003). Reflexive accounts and accounts of reflexivity in qualitative data. Sociology, 37(3), 413-431. doi:10.1177/00380385030373002

Morrow, S. L. (2005). Quality and trustworthiness in qualitative research in counseling research. Journal of Counseling Research, 52(2), 250-260. doi:10.1037/0022-0167.52.2.250

Morse, J. M., Coulehan, J., Thorne, S., Bottorff, J. L., Cheek, J., \& Kuzel, A. J. (2009). Data expressions or expressing data. Qualitative Health Research, 19(8), 1035-1036. doi:10.1177/1049732309338719

Nind, M., \& Vinha, H. (2016). Creative interactions with data: Using visual and metaphorical devices in repeated focus groups. Qualitative Research, 16(1), 9-26. doi:10.1177/1468794114557993

Nortvedt, P., Hem, M., \& Skirbekk, H. (2011). The ethics of care: Role obligations and moderate partiality in healthcare. Nursing Ethics, 18(2), 192-200. doi:10.1177/0969733010388926

Parr, S., Byng, S., Gilpin, S., \& Ireland, C. (1997). Talking about aphasia. Maidenhead, England: Open University Press.

Petrovic, S., Lordly, D., Brigham, S., \& Delaney, M. (2015). Listening to listen: An analysis of applying the Listening Guide to reflection papers. International Journal of Qualitaive Methods, 1-11. doi:10.1177/1609406915621402

Rieger, K., \& Schultz, A. S. (2014). Exploring arts-based knowledge translation: Sharing research findings through performing the patterns, rehearsing the results, staging the synthesis. Worldviews of Evidence Based Nursing, 11(2), 133-139. doi:10.111/wvn.12031

Sorsoli, L., \& Tolman, D. L. (2008). Hearing voices: listening for multiplicity and movement in interview data. In S. N. Hesse-Biber \& P. Leavy (Eds.), Handbook of emergent methods (pp. 495-515). New York, NY: The Guilford Press. 
663

664

665

666

667

668

669
Tracy, S. J. (2010). Qualitative quality: Eight "big-tent" criteria for excellent qualitative research. Qualitative Inquiry, 16(10), 837-851. doi:10.1177/1077800410383121

Tronto, J. (1995). Care as a basis for radical political judgements. Hypatia, 10(2), 141-149.

Woodcock, C. (2010). The listening guide for coaching: Exploring qualitative, relational, voicecentered, evidence based methodology for coaches [Article]. Coaching, 3(2), 144-154. doi:10.1080/17521882.2010.497766 